Received: 28.03.2014.

Reviewed paper

UDK: 303.43 .022

\title{
IN EXPECTATION OF THE THEORY: GROUNDED THEORY METHOD
}

\author{
Danijel Baturina \\ Katedra za socijalnu politiku, Pravni fakultet Zagreb \\ danijel.baturina@pravo.hr
}

\begin{abstract}
This paper explores the grounded theory method as one of the research strategies within a qualitative approach to research which is widely used in social sciences in areas such as sociology, education, political science as well as others. At the beginning we generally indicate what the essence of grounded theory method is. We analyze the steps that form integral parts of the method like data collection, creation of codes and concepts, hypotheses about connections and ultimately generation of the theory. We particularly highlight significant principles that characterize the grounded theory method such as theoretical sampling, method of constant comparison and application of theoretical saturation. Analyses served to comprehend the importance and role of all parts of the process of grounded theory method and requirements which it place upon researchers who want it use it successfully. Apart from detail analyses of every aspect of grounded theory method in possible application of the method, we deal with some criticism, complaints and doubts about how to use the method to realize possible shortcomings. They are related to the general qualitative approach but also to the requirements of methodological rigor that are placed in front of researchers and the specificities related to way of generating theory. Based on the above we discuss the reach of grounded theory method such as its possible applications. In conclusion, we stress the importance and highlight possible future perspective of the grounded theory method as a research strategy within a qualitative approach.
\end{abstract}

Keywords: qualitative research strategy, method of constant comparison, coding, concepts, theory, grounded theory method

\section{Introduction}

This paper will discuss the grounded theory method as one of the strategies of research within a qualitative approach to research. The grounded theory method began with the development in the 60s of the 20th century by American researchers Strauss and Glaser and is primarily articulated in the book The Discovery of Grounded Theory issued in 1967. The grounded theory method generated great interest and was used in numerous studies. Over time it has undergone certain modifications and attempts of new articulation.

With the time the initial approach differentiate to Glaser's approach and Strauss's (and Corbin's) approach. The main difference in approach boils down to the question "Does the researcher use a well-defined paradigm of coding/ systematic observation about causal conditions, phenomena, context, intervening conditions, action strategies and consequences in the data or is it entering the field of research with no idea/ hypothesis/ assumption about what is researching while waiting to fieldof study reveal itself. "(Kelle, 2005, Glaser, 1992 according to Jeđud 2007, 87). In addition to concepts and categories in a systematic process of looking at the data, Strauss adds to contemporary approach propositions. They represent generalized relations between categories and their concepts and between individual categories which contribute to the 
underlying causal connections and data integration in a theoretical framework. (Jeđud, 2007). Also in the later period constructivist grounded theory method experienced significant development. Its essence is in a different view of the interaction between researchers and participants in the research process by highlighting the notion of researcher as author. It is assumed that the data and the theory have not been discovered, but researcher is constructing it as a result of interaction with the terrain and the participants. It focuses on the possible meanings that can be constructed from the data. Researchers are therefore looking and questioning tacit meanings, values, beliefs and ideologies. (Mills et al., 2006).

This paper will firstly present a general indication of the essence of the grounded theory $\operatorname{method}^{7}$. Grounded theory method is a research strategy which is somewhat contradictory to usual manner of conducting research in the social sciences. Instead of relying on the literature or previous knowledge to generate hypotheses which then would be tested to construct the theory, grounded theory method begins with the collection of data which will serve to create codes and concepts, hypotheses about connections and to generate theory. We will investigate the characteristics of theoretical sampling, method of constant comparisons and application of theoretical saturation. The second section will provide a review of the process of coding data. We will analyze open, axial and selective coding as processes in which concepts and categories are generated through data. We will consider the role of literature and notes as one of the integrative parts of the grounded theory method process. The next part of the article will be devoted to the process in which theory as the final product emerges. After that we will address some of the points that were criticized in the grounded theory method. Over time numerous objections and doubts about how to use the grounded theory method have developed. We end up with a conclusion in which we will look at the importance of the grounded theory method as a research strategy within a qualitative approach.

\section{About grounded theory method}

The grounded theory method was developed by two American sociologists. In their book The Discovery of Grounded Theory Glaser and Strauss proposed grounded theory as a practical method for conducting research that focuses on the interpretative process of analyzing "the actual production of meanings and concepts that social actors use in real-life circumstances" (Gephart, 2004, 457). They also reject the positivist understanding of falsification and hypothesis testing. Instead, they describe the organic process of the formation of the theory based on how well the data fit into conceptual categories that the observer established, how good categories are explaining or predicting interpretations, and how relevant are categories for fundamental questions that are observed (Suddaby, 2006). The term grounded theory is used in two ways: (1) as a research strategy which process will produce (2) theory that is grounded in the data, ie. grounded theory ${ }^{8}$. Therefore the research strategy and outcome of research process have the same name ${ }^{9}$.

Grounded theory refers to a specific methodology on how produce conceptual theory from data that was systematically collected. It is used by many researchers in different areas. The procedures are key part and they are not limited by disciplines. Although developed in the field of sociology, it can be successfully applied in other disciplines such as education, patient care, and political science, to some degree in psychology but also in economics and informatics. Jeđud

\footnotetext{
${ }^{7}$ In this paper we will consider the grounded theory method through the concept of Glaser and Strauss, which today represents a starting point to grounded theory method. Other approaches will be used only in critical reflection of possible deficiencies of original approach

${ }^{8}$ Of course this can lead to some confusion in the use of the term grounded theory therefore it is necessary to emphasize that this paper focuses on the first meaning of the grounded theory method as a research strategy within the qualitative approach to research.

${ }^{9}$ http://www.groundedtheoryonline.com/what-is-grounded-theory.
} 
(2007) states that by reviewing the literature it can be seen that is used by researchers in the field of nursing, patient care and research strategies to cope with chronic illness, in the area of institutional treatment of children and young people, in education, family therapy, linguistics and studies of attitudes towards animals.

Grounded theory is a general method. It represents a complete methodological package. It can be used on any data or combinations of data. It provides a series of systematic, precise steps starting with data collection, which is continued by analysis procedures that lead researchers to inductively derive theoretical work that can be published (Glaser, 2010, Strauss and Corbin, 1990). The overall objective of the research is to construct a theory in order to understand the phenomenon. It is a "strategic bond that connects the empirical world with a formal theory" (Halmi, 2005, 222). According to Morse and Field (Eaves, 2001, 655), "the process of creating theory in the grounded theory method is hierarchical and recursive, because researchers systematically categorize the data and are restricting they theorizing until in process of categorizing the data do not show patterns". The theory is developed during the research process and gradually generated through the dynamic interplay between data collection and analysis.

The main assumptions of grounded theory method are summarized by the Eaves (2001). The research is structured towards discovering of social and social- psychological processes. The phases of data collection and analysis are happening simultaneously. The processes and products of research are formed from the data rather than from the preconceptions of logically compelling theoretical frameworks. Analytical procedures are directed towards discovering and developing theories rather than verifying existing theories. Theoretical sampling is used for re-refining, elaborating and exhausting conceptual categories.

The methodology of grounded theory is not only focused on the study of the process, but it is assumed that the construction of a theoretical understanding of social life itself is a process. Systematic application of analytical techniques of grounded theory method progressively leads to more abstract analytical levels. The main assumptions of the grounded theory method give indications that it is a research method that is based on the data, is guided by the analytical processes that are systematic and with the primary goal to develop theory by inductive approach and not by verifying existing theories. After the introduction of the method and summary the initial assumptions, we will continue to focus on analytical procedures and processes of grounded theory method.

\section{Analytical procedures and processes in the grounded theory method}

\section{Basic principles of grounded theory method}

Initiation of research by grounded theory method first involves selecting area of research and appropriate environment for the study. The research area can be described in different ways or levels, including the specific process, phenomenon, place or location, or context. Studies that use grounded theory method should be directed to the detection of emerging ideas or connections and incensement of understanding of the meaning, context, process, and the way in which things happen. Given the complex nature of the research, it is not unusual that it is difficult to locate the research question. Questions are usually general, flexible and open. ( $\mathrm{Ng}$, Hase, 2008). It is important for the researcher to avoid predispositions or biases about the phenomenon. (Egan, 2002). Strauss claims (according to Haig, 1995) that, precisely because it is not necessary to have a pre-articulated problem, scientists can get to their problems at any point in the research process. After formulating the problem, specific research questions are set and they need to be contextual, research, biographical, and organizational. In the way questions are asked we are demonstrating theoretical sensitivity for certain concepts. They are developed from personal experience or knowledge of the subject's literature. At the same time, it is necessary to maintain a balance between rigor of the scientific approach and creativity. 
Another methodological choice is the method of data collection. In the grounded theory method interviews and observations are the most commonly used methods. Focus groups were also shown to be relevant for data collection especially in the beginning of the research (Pergert, 2009). But the fundamental feature of the grounded theory method is that all is data. Not only interviews or observations, but everything that helps the researcher to generate concepts and theory is data. It is claimed that the process of creating a theory is independent of the types of data that are used (Glaser and Strauss, 1967 to Cerniglia 2008).

Question of sampling in the grounded theory method is also very important. Initial decisions about sampling are based on the general subject area. Initial decisions on the number of observations or interviews depend on the approach, the resources, the research objectives, and the time and energy. There are similarities with intentional sampling in the sense that the goal is to include people who are "full of knowledge" about a case we are studying (Polit and Hungler, 1999). Initial sampling represents a starting point, not theoretical elaboration. We cannot assume that we know our categories in advance, especially if we include them in the initial research questions. It is necessary to find relevant material for research, "regardless of whether it would take you up to sampling of people, the environment or larger structures such as government agencies or organizations" (Charmaz, 2006, 100). Starting or initial sampling is followed by theoretical or purposeful sampling. It is a process of collecting data and selecting a group or category based on their relevance to the research questions, a theoretical position, analytical practice and theory that we develop. Sampling is used to develop the emerging theoretical categories. It is therefore primarily used for conceptual and theoretical development, and it is not intended to represent the population or increase the statistical generality of results. That separates theoretical sampling from other types of sampling. Some qualitative research may claim to use theoretical sampling but often they do not use logic of grounded theory method. Often theoretical sampling is mixed up with sampling to reflect population distribution, sampling to find negative examples and sampling until the new data appears (Charmaz, 2006).

The basic question is what data to collect and where to find them. In the process of data collection, the researcher simultaneously collects, codes, and analyzes his data and decides what data to collect next and where to find them, in order to develop the emerging theory. (Pergert, 2009). The data collection process is controlled by the formation of the theory. (Glaser and Strauss, 1967 to Cerniglia, 2008). As the theoretical sampling occurs in tandem with the common processes of collecting and analyzing data, it can be confusing and pose a major challenge to researchers.

So in the initial phase of data collection all available data are collected and all that appears in the field is treated as data. In a later stage we are applying the method of constant comparison and logic of theoretical sampling to collect only those data, in those categories, which will provide meaningful comparisons and lead us to development of the theory. Yin conceived theoretical sampling similarly (according to Pandit, 1996). He mentions two kinds of theoretical sampling, initially and subsequent. In the initial sampling, we collect all the data and after that, subsequent sampling has three specific purposes. 1.Case that will fill the categories and expand the emerging theory, 2. Case that will replicate previous case to developed theory 3.Case which is contrary to the previous case to expanded / modified theory. The aim is to provide a sample that not only helps in the development of theory but is also testing it. Complete "immersion in the details" is necessary for that phase. The researcher should demonstrate how rigorously he examined cases that do not fit into his ideas. In this way the theory that arises is strengthened or modified in accordance with the new data that are emerging.

The criterion for judging when to stop with theoretical sampling and data collection is theoretical saturation or just saturation. Glaser and Strauss (according Pandit, 1996) indicate that saturation is achieved in the case when by obtaining new data we cannot develop new category. When you see that similar things are repeated enough times, the researcher can be sure that a certain category is saturated. Marburg et al. (2004, according to Jeđud 2007) give practical advice 
for researchers (ie. Rule of tumb). It is necessary to interview/ collect data until we do not hear anything new. Then it is necessary to interview one more person to be sure. Intensive development of properties creates conceptual density needed to lift the theory above description and allow its integration through theoretical propositions (hypotheses) as an abstract conceptual theory. Once the category is saturated there is no need for further theoretical sampling for the collection of data that would be used to compare cases (Glaser 2001 to Holton, 2010).

When we start with the collection and analysis of data one of the most important prerequisites for the successful use of the grounded theory method is certainly a theoretical sensitivity, which includes the ability to conceptualize. Theoretical sensitivity is defined as "the ability of researchers to identify the important characteristics of the data collected (variables and relationships) and to give them meaning in order to adequately reflect the phenomenon that is being investigated" (Jeđud, 2007, 87). Theoretical sensitivity is crucial at all stages of the grounded theory method because without it concepts and categories will not be properly identified which would result in deficient theory. It requests from researcher's exceptional analytical ability and ability to notice the abstract connections. Glaser and Strauss (1967, according to Birk, Mills 2011) explain criteria's of theoretical sensitivity as two parts of the concept. First, the researcher's theoretical sensitivity level is deeply personal. It reflects a level of insight into yourself and the area you are investigating. Secondly, the researcher's theoretical sensitivity level reflects their intellectual history, types of theories that they have read, absorb and now use in everyday thinking. The researchers are sum of all that they have experienced. Theoretical sensitivity is the key element for the developed theory to reflect the real nature of the phenomenon being studied.

Another key feature of the grounded theory method is consistent use of constant comparative method throughout the entire analytical process. Basic, defining rule of the constant comparative method is that, while the encoding indicator for the concept that indicator is compared to the previous indicators, which are coded in the same way. The indicator refers to words, phrases, or sentences, or a string of words, phrases, or sentences, in the analyzed materials. The concept is the mark or the name associated with the indicator ie., "the concept is a symbol or a conventional sign attached to the referent" (Laross, 2005, 841) As already stated, the constant comparison of variable parameters in the data reveals the characteristics and dimensions of each concept or category. This process of constant comparison continues until new characteristics or dimensions a stop appearing. (Holton, 2010). The constant comparative method is designed to assist the analyst in creating a theory that is integrated, consistent, and plausible, close to the data and at the same time is in sufficiently clear format to be ready for operationalizion and testing in quantitative research (Cerniglia, 2008).

\section{Types of coding in the grounded theory method}

Conceptualization of data is the key to grounded theory development. Coding is leading researcher outside the empirical level by "breaking" the data, then conceptualising the initial sample of set of empirical indicators within data for the development of a theory that explains what is happening in the data. Coding gives the researcher shortened abstract view of the scope and dimensions that comprise otherwise seemingly disparate phenomena (Holton, 2010). In grounded theory, coding process is also significant because the coding constantly encourages conceptual ideas. Researchers encode as many categories as possible in which they can fit different incidents. Incidents are empirical data (indicators categories or concepts) of which grounded theory is generated. New categories and new incidents appear and are fitted into the existing categories. Coding can have very unpleasant feeling in the beginning, and the researcher may feel uncertain about labelling codes, but this feeling of insecurity gradually decreases with continued efforts in the analysis. (Holton, 2010, 24). Pattern recognition gives the researcher the confidence in the process of coding, encourages researchers to continue. It offers guidance where to go in data collection, coding and building categories in the analysis process or phenomenon. A 
further part of the paper will analyse the types of coding that occur in the grounded theory method process.

\section{Open coding}

Open coding is part of the analytical process which is particularly focused on signification (labelling) and categorizing the phenomenon through the process of gathering the data. (Halmi, 2003). In an open coding "data are "broken,, into discrete parts, closely examined, in relation to the similarities and differences and questions how phenomena are reflected in the data is asked" (Laross, 2005, 841). Researcher examines data "line by line" and by comparing incidents in the data, the researcher encodes data in every possible way and continues with asking a series of questions about the data. Product of labelling and categorizing are concepts - the basic construction building blocks grounded method theory (Pandit, 1996). Sampling in the open coding is used for the purpose of establishing, as much as possible, categories, together with their characteristics and dimensions. As it is not clear which concepts are relevant sampling is open to the people, places and situations that provide the greatest opportunity to gather the most relevant data on the phenomenon under study. (Strauss, Corbin, 1990.181).

Glaser (1978, according to Jeđud, 2007) proposes three key questions that guide the process of open coding 1 . What is this data indicating 2 . What category this event indicates, 3 . What is really going on with the data? When you establish a certain variation in the data you formulate research questions about how the investigated phenomenon is reflected in the collected data. Through this process we have successive assumptions about the phenomenon in the form of questions that lead to new discoveries and challenges. First, incidents are compared in relation to other incidents to establish a basic uniformity and varying conditions of generated notions and hypotheses. Then, emerging concepts are compared with the number of incidents in order to generate new theoretical properties of concepts and further hypotheses. The purpose is the theoretical elaboration, saturation and thickeners of the concepts. Concepts are not only representatives of the reality/events; they generalize them and indicate their features on a more abstract level. Concepts are actually a step towards the construction of categories, by grouping of concepts categories are generated. Finally, established concepts are compared with each other for three purposes to provide the best fit between potential concepts and set of indicators, on conceptual level between the terms that refer to the same set of indicators and also for their integration into hypotheses to form a theory.

\section{Axial coding}

Axially or axial coding is the second stage of the process of coding of data that continues to open coding. Axial coding is the process of conceptualizing the empirical substance of studied area, the data on which the theory is based. The process goes from the initial open coding of data towards the emerging of central category, followed by demarcation of data collection and analysis for the selective coding to theoretically determine the central category and related categories. (Holton, 2010).

Researcher uses axial coding in two ways: first, to develop completely individual categories by merging subcategories, in order to develop their properties and dimensions, and, secondly, to link the categories together. Data are connected in ways that are conceptually more abstract than in the open coding. (Birk, Mills, 2011). Focusing on categories solves the problems of compatibility, relevance, forcing and the "abundance". Type of categories that should occur have two common features. First, the terms must be analytical - sufficiently generalized to signify characteristics of specific entities, and not entities themselves. They should also be sensitizing to be able to contribute to meaningful picture. (Cerniglia, 2008). Axial coding establishes relationships within the category, between the categories and subcategories. Data in the form of categories recombine established connections / relationships. These relationships are then tested 
with new data. Parallel analysis and data collection are done in order to minimize the possible emergence of ambiguities in the theory that will be created. We, through the coding process, set some hypotheses which are then tested, and critically assessed on the new data (Jeđud, 2007, 91). Axial coding aggregates data in a new way by integrating categories and subcategories in the transaction system. In axial coding, "all subcategories are associated with the central category and make sequential chain" (Halmi, 2006, 352-353). In axial coding, sampling focuses on discovering and validating relationships between categories. Axial coding consists of "intensive analysis around a category (ie. variable) in certain time, in terms of the paradigm of category" (ie. condition, result, interaction between actors and so on) (Strauss, 1987 by Larossi, 2005, 846).

\section{Selective coding}

In order to reach a grounded theory it is necessary to integrate all categories in a meaningful way. The integration process in the selective coding is very similar to the axial only here the actions are on the highest level of abstraction. We understood selective coding as a process in which all categories unite around one (sometimes more than one) central category. It is a process of "selecting a central category, systematic discovery of substantive relations between the other categories, the validation of these relations and filling the categories with new elements for the purpose of their further development and sophistication" (Halmi, 2003, 361). Those category/categories that have the greatest strength in explaining a phenomenon are called central category/categories. Selective coding begins only after the researcher has identified a potential central category. The central category has a higher frequency and is more aligned with the other categories. (Dick, 2005). In order to integrate categories and form the theory sampling in the selective coding should be direct and intentional, so called discriminate sampling. In discriminant sampling researcher chooses locations, people or documents that will maximize the chance to confirm the story lines, the relations between categories, and fill up underdeveloped categories. (Strauss, Corbin, 1990,187). This coding occurs in later stages of research at the moment when the researcher has discovered the central category. Data collection and coding that follows is limited to what is relevant for the emerging conceptual framework. By focusing on the central and other related categories the further data collection can go very quickly.

Central category can be any kind of theoretical code: process, typology, continuum, range, size, condition, consequence, and so on. Its primary function is to integrate theory and make it dense and saturated. In an attempt to explain how the main problem is continuously processed or handled, central category becomes the focus of selective data collection and coding. It takes time and a lot of coding and analysis in order to confirm a central category through saturation, relevance, and applicability. (Holton, 2010). Central category is revealed as it occurs through an iterative coding, conceptual recording, and theoretical sampling of further data in purpose to develop conceptual guidelines, ensuring that all terms have their role in the emerging theory. Selective data collection and analysis continues until the researcher does not have the central category that is enough elaborated and integrated as well its properties and its theoretical links with other relevant categories. Selective coding is essential for theoretical integration.

In addition to different types of coding, it is important to consider the role of notes and literature that have a significant contribution in building a theory based on collected data.

\section{Role of notes and literature}

In this section we will look at making notes as an important aspect of the entire process of discovering of theory. Also we will reflect what role does literature have and what are use ways in which can be used in the grounded theory method.

Noting leads a process of discovering a theory and suggests the way by which the data and categories rise above the level of description on the level of theory/conceptualization. Writing gives the possibility to record all ideas, detach yourself and think about the categories that are 
occurring. Making notes is actually an instrument of a flow of thoughts / ideas. Making notes is a continuous process that helps raise the data on the conceptual level and develop properties of each category. Noting also lead the next steps in further data gathering, coding and analysis.

Early in the process, the notes result from the constant comparisons of indicators with indicators, then the indicator with the concepts. These notes are often very short, only a few lines. Later notes are more extensive, they integrate ideas of earlier notes, and creating new notes raise the level of conceptualization further. (Holton, 2010). Sorting and writing notes creates additional notes. There are three kinds of notes (Mills, Birk Clarke, 2005). 1.Notes about codes- conceptual labelling in the process of open coding. 2. Theoretical notes- developing of theoretical ideas in the process of axial and selective coding. 3.Operative notes -guidelines related to the unfolding of research, eg. With whom is no need to talk, what else needs to be done. Notes can be considered "intellectual capital in the bank" (Mills et al. 2005, 85). Making notes slows the researchers, forces them to "reasonably look at categories, their integration and the relevance to the theory" (Jeđud, 2007, 93).

Notes are written records of the researcher's thinking during the process of grounded theory research. The main objective of the notes is to develop ideas with complete conceptual freedom. Notes are stored and subsequently sorted to facilitate integration of the entire theory. Imagination and creativity are used in writing notes and are necessary to achieve the theory that improves knowledge and understanding.

On the other hand, the question of the role of literature in the grounded theory method is also vital. Through previous literature researcher can (according to Glaser and Holton 2004) develop some assumptions about what could found in the data and therefore become less sensitive to collected data. Under conscious or unconscious influence of other people's ideas researcher can categorize collected data according to other people's concepts and thus can close itself for further analysis and development of the theory. Wide reading is therefore recommended and it is advised to avoid the literature closely associated area that is being investigated. Reading of technical literature, research reports, theoretical and philosophical works are aspects that belong to wide reading (Pandit, 1996). Cutcliffe (2000, according to Heath, Cowley, 2004) suggests that decisions on the literature depend on two factors. The first decision concerns issue does the researcher have a little knowledge about the phenomena and processes which he is interested in and is not sure about the best approach, or is it aware that there is a lack of knowledge and decides to use a grounded theory method. Second argument for the previous literature reading is that it is necessary if a researcher wants to clarify concepts and to build a new theory on them.

For Glaser's (1978, according to Heath, Cowley, 2004, 143) prior understanding should "be based on the general problem area and the reading should be very broad in order to be sensitive to wide range of possibilities." At the same time, he believes that learning and not knowledge is crucial for maintaining the sensitivity of the data. More focused reading occurs only when the emergent theory has developed enough to allow that literature can be used as additional information. Another way of using literature is that literature is studied later, when relevant concepts and categories are discovered. Literature is treated as one of the data. For Dick (2005) goal of reading literature is its comparison with the emerging theory in the same manner in which we compare other data.

The real danger of prior knowledge in grounded theory is not that it will contaminate the researcher's perspective, but that it will force researchers to test hypotheses, consciously or unconsciously, rather than make direct observations. The reality of the research, based on grounded theory is that it is trying to achieve "practical middle ground between worldviews guided by theory and unfettered empiricism" (Suddaby, 2006, 635). 


\section{In expectation of the theory}

The main goal of grounded theory method is to build a theory that is based on actual data. A researcher who investigates is trying to understand a particular phenomenon by looking at the similarities and differences in the data collected from the field. After coding is completed (or in parallel with it) process of sorting materials, classifying the fragmented data and organization of ideas follows. The grounded theory method provides a comprehensive explanation of the process or the schemes in respect to certain phenomena.

In analyzing the data, a researcher at the micro level is trying to "look for links that exist within the data and assume their relationship with phenomena" (Omar et al., 2010, 277). The grounded theory method allows the researcher to immerse himself and to be completely familiar with the data. Entire process of discovering a theory is the search for meaning. This level of awareness and data analysis makes the grounded theory method long, difficult and hard for researchers. The theory that derives from the researcher's data collection and analysis is in one sense the equivalent of what he systematically knows about his data. From the perspective of grounded theory, theories are sets of related propositions, while propositions state how the variables are related. (Laross, 2005). As the theory integrates it is reinforced with less and less changes that are needed as researcher compares the next incidents in categories with its properties. As the theory develops it becomes reduced, and better in configuring the massive amounts of data, and the researcher becomes attached to it (Holton, 2010).

Developing a systematic analysis allows the researcher in the field to literally write instructions, so that other outsiders can learn about observed spheres of life and activity (Cerniglia, 2008). The researcher should be able to tolerate confusion and hard work with a constant comparison in waiting for the appearance of concepts. Deduction and verification are in the service of emergency. Generated ideas should be checked to all data. Categories are constantly re-fit by constantly comparing incidents in the old and new data. It is necessary that the researcher persistently checks ideas (Glaser, 2001, according to Heath, Cowley, 2004).

The main concern of researchers who engage in grounded theory adventure is whether the theory would appear. The process of creating theory also implies a longer period of uncertainty because there is no pre-defined hypothesis to be tested, there are no specific protocols and lot of patience, hope and perseverance is needed for things to become clearer. The steps in this process are sometimes small and fears are growing that the research will remain unfruitful. Common advice is to remain open and allow the theory to appear. The process and its outcome will often be described as "the path from agony of uncertainty, being overwhelmed by the data to the ecstasy of discovering a theory by researching by the principles of grounded theory" (Jeđud, 2007, 96). If a researcher has confidence in himself and the method, he takes research from a position of "ignorance" and "injects life" to the concept or idea (Glaser 2001). As Glaser $(2001,72)$ states that "it is hard to bear when the normative is so close. But we should also remember that the emergence happens quickly". The answer is in the grounded theory method.

After generation of theory me must considered and think about process of evaluating of grounded theory method. Glaser and Strauss (according to Cooney 2011) pointed out two main criteria for evaluating the adequacy of the grounded theory that has emerged. It has to fit the situation and it needed to be good in helping the people involved to make sense of their experiences and to better manage the situation.

On the other hand looking back on the whole process Charmaz (2006) as the criteria for evaluating grounded theory method states credibility, originality, resonance and utility. For each of these she specifies a series of questions that need to be responded affirmatively to satisfy the criteria. Strauss and Corbin (1990) in a broader approach to the evaluation identify four key areas to consider when assessing the validity of the research based on the grounded theory method, These areas include (a) a judgment on the validity, reliability and credibility of data, (b) judgment of the theory itself, (c) decisions concerning the appropriateness of the research process through 
which the theory has been generated, elaborated, or tested, and (d) conclusions about empirical foundations of the research.

\section{The main criticisms of grounded theory method}

Application of grounded theory method requires considerable exposure to the empirical context of research subject area. The grounded theory method urges researchers to be neutral and impartial as possible about the investigated elements and let the data speak for themselves. The researcher is not completely detached observer. We come to the question of researchers biases as one of the difficulties. (Marburg et al., 2004. according to Jeđud, 2007). Contrary to the prevailing ideal of scientific detachment from the context, the constant comparative method implies close and lasting relationship between the researcher and the research place.

Because of this close and long-term relationship researcher personality, experience and character are becoming important components of the research process and should be an explicit part of the analysis. From this we derive two important consequences. First, in grounded theory, it is necessary for researcher to account their positions in the research process. What is required is a constant reflection to ensure that the personal biases and world views are taken into account in the collection, interpretation and analysis of data. Second, since somewhat artificial boundaries between researchers and research subjects are removed, the quality of contact between researchers and the empirical situation and quality of produced research are in direct relationship (Suddaby, 2006). It is quite clear that the researcher can hardly remain completely unbiased and at the same moment so "immersed" and linked to the data. Objectivity of research can be increased through rigorous requirements of grounded theory method, but can't be fully achieved, which is characteristic of all qualitative research.

Another issue of criticism is related to the choice of research problems. Without previous of literature it is difficult to conceive research problem. The grounded theory method recommends not studying literature before entering the research because it would be a bias towards research. Instead, the literature review should be undertaken after as an independent analysis, purely based on the information at hand, without any prejudice. This orthodox approach is in contrary to the fundamentals of other research methods that start with the problem and review of the literature, which would help to solve the problem, not the other way around. By Popper's words (according to Weiss in 2011,4$)$ "insight does not start with ideas or observations or collecting data or facts, but begins with the problems". There is no knowledge without problem - but also no problem without knowledge. Therefore the question remains how to focus research without pre-set problems. It could be argumented that reality is too difficult to be reconstructed from the data itself in situation in which we do not rely on the already achieved knowledge in the research subject area.

One potential criticism grounded theory method is that it produces huge amounts of data through a lengthy, difficult and absorbing process of collecting and analyzing data. In addition to making it challenging, lot of data can produce a lot of "noise and chaos" to researchers who are trying to deal with them. Therefore the method is generally recommended to be used by experienced and capable researchers. Imperative for the research is to be armed with patience in its application.

The grounded theory method is detailed and repetitive research process. The criticism may be that epistemological rigorous and objectification of all parts of research process can be limiting for the analysis and creativity of researchers. The researcher can feel cramped in respect of strict procedures and feel the lack of freedom in the interpretation of data (Weiss, 2011, 4). Requirements of research can manage the data more than a researcher can use its research capabilities. It may also lead to poor cost-benefit ratio, ie. more pragmatic approach can give greater research effectiveness. This could result in a limitation of the researchers in their thoughts and ideas in situation in which they think that the existing concepts and categories of work. 
Frequent lacking in use of grounded theory method is the failure of "rising" of data on a conceptual level. The transition from relatively superficial observations to abstract theoretical category is achieved by constant interaction between data collection and analysis, which is constant comparative method (Suddaby, 2006). Studies have a tendency to present incomplete or relatively "undigested" data which may reflect irregularities in compliance with the procedures of grounded theory method as well as theoretical insensitivity and researcher lack of ability to conceptualize.

In the research it may happen that the term grounded theory is often interpreted to mean that "anything goes". Data are collected randomly, coded by forced application of existing conceptual categories, and are used to test hypotheses. Some research ignores or deliberately violates the underlying processes and principles of grounded theory method (Suddaby, 2006). Therefore, in the studies that claim to use the grounded theory method methodology should be sufficiently transparently described. It should be indicated how they incorporate the basic analytical thesis in generating data and that be able to assess how the information's are used for generation of the key conceptual categories.

Furthermore regarding discovering of theory it remains a question can inductive approach of grounded theory method really produce a theory or is it just offering interpretation or inductive arguments, which eventually boils down to the question of what is considered a theory. Fendt and Sachs, (according to Weiss, 2011) are proposing to alleviate the promise of generating theory in method and argue that grounded inquiry is more appropriate designation for a grounded theory method.

Finally already the title of pioneer work "discovery of grounded theory" implies that there is a theory out there that stands on neutral ground, ready to be discovered. The implicit assumption is that it will "emerge" from the data. Thomas and James (according to Weiss, 2011) have a number of criticisms of the idea. First they claim that a free spirit in the minds of researchers which would enable them to neutrally and inertly put some cognitive frames on collected data does not exist.

So they can't discover theory unbiased from information which it is based. Next grounded theory as well as the terms is a product of cultivated mind. These products have not been discovered, but as the authors explain invented which means that the grounded theory is constructed or invented on the basis of the researcher's interpretations and insights. This question goes to the heart of interpretation and understanding which created from qualitative research.

\section{Discussion}

The methodology of qualitative research is characterized by "way of interpreting social reality by interpreters who do so from the perspective of the research subjects" (Halmi, 2005, 219). Within qualitative approach grounded theory method was profiled as a special research strategy used in many fields such as sociology, education, medical science, political science as well as others where it can be shown purposeful. Grounded theory is not only focused on the study of the process, but it is assumed that the construction of a theoretical understanding of social life itself is a process. In grounded theory researcher humbly allows data to control him as much as humanly possible, to write a theory that comes from his induction skills. The integration of substantive theory that comes from coding and sorting is a way of testing does hypotheses and concepts fit, are they functional and relevant enough. They have not been proven, they are theory (Glaser, 1992, according to Holton 2010).

Some of the immanent characteristics of grounded theory method, compared to others is that, are that in many pre-designed methods of verification, data are poor, not the theory. Secondly, grounded theory shows that all data, regardless of their quality, may change theory through comparison. This modification of the theory is crucial because modifications allow us to constantly keep up with what is going on the field while the changes are occurring and that enhances theory's formal abstraction. By that we constantly correct poor information and are 
making the theory that is more grounded (Glaser, 2010). Researcher in grounded theory should have three important characteristics: "the ability to conceptualize the data, the ability to tolerate some confusion, as well as ability to tolerate a regression that confusion carries with it". (Glaser, 2010, 4).Grounded theory method can be considered constructed on the following principles: a vast amount of data is collected before the connection/ relationship between the categories are made and saturation of data will not be achieved if the data is insufficiently analyzed or do not show recurring regularities.

The largest contribution of grounded theory method is that it made a qualitative more legit. It provides the means to carry out systematic and detailed analysis of the data and gives researchers enough evidence to support their claims. Constant comparative method and theoretical sampling are considered particularly useful in this as well in encouragement of the constant interaction between data collection and analysis. Although the method has rigorous requirements it is also open to different possible ways of interpretation in aim to get to the theory.

From the original approach of Strauss and Glaser, there have been numerous variations and adaptation of the method. The researchers attempted to use its principles in different ways trying to adapt it better in an attempt to transform empirical data into meaningful theory. In the debate on the future of grounded theory method Strauss and Corbin (1994, according to Eaves, 2001) predict that: (a) researchers will, in various professional fields and countries, experiment and will use or adapt the methodology, (b) adaptation will include a combination of grounded theory method with other methodologies, qualitative and quantitative, and (c) researchers will expand and make certain changes in the procedures of grounded theory method to maximize the utility of the method for a wider range of phenomena.

\section{Conclusion}

The grounded theory method, whose main elements, procedures and criticisms are presented in this paper, is extremely demanding and challenging research strategy. There are many preconditions for its effective use. Data collection occurs over the long term, on many levels to ensure significant results. It is necessary to be fully immersed in the data, which requires a lot of time and effort. To make it more effective, it is necessary to rigorously follow the research procedures and develop a theoretical sensitivity to be able to meaningfully shape the data. The findings are constantly redefined and negotiated until we come to the end product, the theory based on data. It is also inventive and creative research strategy where the researcher is trying to make sense and meaning of the studied social phenomena and come up with a theory that will be relevant.

Researcher stands "alone with the data" completely immersed and is trying to theoretically conceptualize what empirical situation is offering to him. It demands fully devoted researcher with well-established research skills and therefore is very challenging for young researchers and is recommended to be used by more experienced researchers

It can be concluded that in its characteristics grounded theory method is primarily intellectually stimulating and constantly challenging for researchers. The grounded theory method is systematic and open but in a way that allows the researcher "space for moving". A researcher who uses the grounded theory method can be compared to a detective. There is a puzzle or mystery in one part of social reality. Researcher is trying to find a process that happens in the background and to understand what is not clear. Many areas of social research in Croatia are in the need for usage of the grounded theory method. In a relatively small research community, numerous topics remain unknown and undiscovered empirically. Therefore, grounded theory method can be a challenge for exploration and contribution to the actualization of neglected areas of research in areas such as education, sociology, social work, political science and other as well as deepening the knowledge or forming new theoretical approaches on topics that were partially researched. 


\section{References}

1. Birks, M., Mills. J. (2011). Essentials of grounded theory. In Birks, M., Mills, J. (Ed.), Grounded Theory, A Practical Guide (pp.1-14). London: SAGE Publications Ltd.

2. Calin, M., Weiss, S. (2011). What is grounded theory? Seminar Thesis- In the context of the doctoral seminar "Research Methodology I", ETH Zurich and University of St. Gallen.

3. Cerniglia, A. J.(2008). Excerpts from: The Discovery of Grounded Theory: Strategies for Qualitative Research by Barney G. Glaser and Anselm L. Strauss (http://andrewcerniglia.com/documents/The_Discovery_of_Grounded_Theory.pdf).

4. Charmaz K. (2006). Constructing grounded theory. A practical guide though qualitative analysis. London: Sage publications,

5. Cooney, A. (2011) Rigour and grounded theory. Nurse Researcher, 18(4), 17-22.

6. Cutcliffe, J. R. (2005). Adapt or adopt: developing and transgressing the methodological boundaries of grounded theory. Journal of Advanced Nursing, 51(4), 421-428.

7. Eaves, Y. D. (2001). A synthesis technique for grounded theory data analysis. Methodological Issues In Nursing Research, 35(5), 654-663.

8. Egan, T. M (2002). Advances in Developing Human Resources. Grounded Theory Research and Theory Building , 4(3), 277-296.

9. Glaser, B.G. (2009). The Novice GT Researcher. The Grounded Theory Review, 8 (2), 128.

10. Glaser, B. G. (2010). The Future of Grounded Theory. The Grounded Theory Review, $9(2), 1-15$.

11. Haig, B. D. (1995). Grounded Theory as Scientific Method, Philosophy Of Education (http://www.steerweb.org/research/FRM/sample/Haig\%20Grounded\%20Theory\%20as $\% 20$ Scientific\%20Method.pdf).

12. Halmi, A. (2005). Strategije kvalitativnih istraživanja u primjenjenim društvenim znanostima, Jastrebarsko: Naklada Slap.

13. Heath, H., Cowley, S. (2004). Developing a grounded theory approach: a comparison of Glaser and Strauss. International Journal of Nursing Studies, 41, 141-150.

14. Holton, J. A. (2010). The Coding Process and Its Challenges. The Grounded Theory Review, 9(1), 21-41.

15. Jeđud, I. (2007). Alisa u zemlji čudesa- Kvalitativna metodologija i metoda utemeljene teorije, Hrvatska revija za rehabilitacijska istraživanja, 43(2), 83-101.

16. Kelle, U. (2005.): "Emergence" vs. "Forcing" of Empirical Data? A Crucial Problem of "Grounded Theory" Reconsidered. Forum Qualitative Sozialforschung / Forum: Qualitative Social Research, 6 (2): Art. 27, (http://nbn-resolving.de/urn:nbn:de:0114fqs0502275).

17. Mills J., Bonner A., Francis, K. (2006). The Development of Constructivist Grounded Theory. International Journal of Qualitative Methods, 5(1), 1-10.

18. Mills J., Chapman Y., Bonner A. \& Francis K. (2007). Grounded theory: a methodological spiral from positivism to postmodernism. Journal of Advanced Nursing, 58 (1), 72-79.

19. Ng, K.,Hase, S. (2008). Grounded Suggestions for Doing a Grounded Theory Business Research. The Electronic Journal of Business Research Methods, 6(2), 155 - 170.

20. Larossa, R. (2005). Grounded Theory Methods and Qualitative Family Research, Journal of Marriage and Family, 67(4), 837-857.

21. Omar, A. H.H. Hamid, D. H.T.A.H., Alias., Islam. Md. R. (2010). Grounded Theory: A Short Cut to Highlight a Researchers' Intellectuality. Journal of Social Sciences, 6(2), 276-281. 
22. Pandit. N.R. (1996). The Creation of Theory: A Recent Application of the Grounded Theory Method. The Qualitative Report, 2.44 (http://www.nova.edu/ssss/QR/QR2-4/pandit.html) (11.09.2013)

23. Pergert, P. (2009). Methodological Learning-by-Doing: Challenges, lessons learned and rewards. The Grounded Theory Review, 8 (2), 65-77.

24. Roderick, C. (2009). Learning Classic Grounded Theory: An account of the journey and advice for new researchers. The Grounded Theory Review, 8(2), 49-65.

25. Strauss. A., Corbin J. (1990). Basics of qualitative research. Grounded theory procedure san technique. London: Sage Publications.

26. Suddaby, R. (2006). What grounded theory is not. Academy of management journal, 49(4), 633-642.

Web sources: http://www.groundedtheoryonline.com/what-is-grounded-theory (12.06.2013). 